\title{
Investigation of Hot Machining Process on Oil Hardened Non Shrinking Steel Using TiAlN Coated Carbide Tool
}

\author{
R.Rajeshkannan ${ }^{1}$, P.Rajasekar ${ }^{2}$, G.Arulmurugan ${ }^{3}$, V.Anand ${ }^{4}$ \\ ${ }_{1,2,3,4}$ Assistant Professor, Mechanical Engineering Department, Pavai college of Technology
}

\begin{abstract}
In the current scenario, there is a need of materials with very high hardness and shear strength in order to satisfy industrial requirements. Machining of such materials with conventional method of machining was proved to be very costly as these materials greatly affect the tool life. So to decrease the tool wear and better surface finish, Hot Machining is preferred. This paper presents an investigation on the effect of cutting parameters on multiple performance characteristics (material removal rate and the work piece surface roughness) obtained by hot turning operations. A plan of experiments based on the Taguchi method was designed and the experiments were carried on oil hardened non shrinkage steel (OHNS) with Titanium Aluminium Nitride coated carbide insert (TiAlN) as tool and the work piece is heated below its recrystallization temperature by oxy oxyacetylene flame was machined under different settings of feed rate, depth of cut, cutting speed and work piece temperature on a lathe. The results of the study indicate that feed rate has the most significant effect on surface roughness. Cutting speed and feed rate has the most significant effect on material removal rate.
\end{abstract}

Key terms: Hot turning, TiAlN Insert, OHNS, Surface roughness, Tool Wear, Taguchi DOE.

\section{Introduction}

Hot machining is the process which is used for easy machining and to eliminate the problems of low cutting speed, feeds and heavy loads on the machine bearings. These problems arise when machining process is being done on the new and tough materials. The basic principle behind this process is the surface of the work piece which is to be machined is pre heated to a temperature below the re-crystallization. By this heating, the shear force gets reduced and machining process becomes easy. During the machining process, instead of increasing the quality of the cutter materials, softening of the work piece is one of an alternate. In hot machining, a part or whole of the work piece is heated. Heating is performed before or during machining.

The selection of a heating method for obtaining ideal heating of metals for machining is critical. Faulty heating methods could induce unwanted structural changes in the work piece and increase the cost. In research, many heating methods are utilized. The methods mostly used are electrical resistance and plasma arc heating.

Some of the advantages of hot machining process are,

1. Easy formation of chip

2. Lessened shocks to the tools

3. Good surface finish of the work piece

On other hand the main disadvantage of this process is the work piece micro structure may get disturbed due to heating. To overcome the disadvantages during hot machining, some basic requirements have to be taken. They are as follows.

\subsection{Basic Requirements of Workpiece Heating Technique:}

1. The application of external heat should be localized at the shear zone, just ahead of the cutting edge, where the deformation of the work piece material is maximum

2. Heating should be confined to a small area as possible, so that the dimensional accuracy can be tolerated.

3. The method of heat supply should be incorporated with fine temperature control device as the tool life is temperature sensitive.

4. Machined surfaces must not be contaminated or over heated, resulting in possible metallurgical change or distortion to the uncut material.

\section{Literature Survey}

OHNS steel is most commonly used in manufacturing for tool and dies and it finds many applications like Lay shafts, Wheel axle, gears and Fasteners due their high hardness, strength and weight ratio. OHNS steel has following chemical composition by weight: C 1.02 , W $1.31 \%$, Si $0.197 \%, \mathrm{Cr} 0.682 \%, \mathrm{Mn} 0.522 \%$, Ni $0.0808 \%, \mathrm{~S} 0.0508 \%, \mathrm{Cu} 0.0548 \%$, Mo $0.00416 \%, \mathrm{Al} 0.0195 \%, \mathrm{~V} 0.0031 \%$ Rest is iron with additives. 
S. Ranganathan et al stated that while turning of materials, which have high strength, wear resistance and toughness exhibit lot of difficulties, while doing by conventional machining methods and yields desirable results only by the selection of optimum machining parameters. Non-conventional machining techniques such as abrasive jet machining, electro chemical machining and electrical discharge machining processes remove a very small amount of material in every pass, which is very expensive and consuming more time as well. Hence, hot machining process has been developed in industries to remove large amount of materials without compromising machining and quality.

M. Davami et al classified hot machinable materials in four Groups aaccording to their composition and properties. These classes are

(i) chilled cast iron, (ii) steel with hardness over $50 \mathrm{HRC}$, (iii) steel whose surface is hardened with cobalt and other additional alloys and (iv)Steels hardened by cold working. Many researchers have used different heating techniques like laser heating, plasma heating, induction heating; electrical heating and they were proved that these heating techniques are expensive. Several researchers reported that there is an improvement in both surface finish and tool life in hot machining (Akasawa et al., 1987, Ueharaet al 1986., Hinds et al 1980, Raghuram et al., 1979, Chen et al., 1973, Pal et al., 1969). Larin and Martynow discussed the method of heating during machining of steel. Kitagawa et al discussed plasma hot machining for glasses and engineering materials, such as, Pyrex, Mullite, Alumina, Zirconia, Silicon nitride and sintered high speed steel. Pal et al investigated the tool life during hot machining of Austenitic Manganese Steel and they reported that the tool life is dependent on work piece temperature and relative cutting speed.

Chen and Lo et al presented the experimental investigation of the factors that affect the tool wear in the hot machining of alloy steel. L.Ozler et al investigated influence of temperature on tool life in hot machining of austenitic manganese steel. K.P.Maitey, P.K.Swain developed tool life equation for hot machining by experimental results, work piece was heated by flame of LPG and oxygen. Surface roughness is important parameter from quality point of view and it also reduces manufacturing cost. N.Satheesh Kumar et al experimentally analyzed effect of spindle speed and feed rate on surface roughness of carbon steel in CNC turning; they concluded that good surface finish was achieved by low feed rate and high spindle speed.

Lei et al., 2001 stated that, In hot machining a part or whole work piece is heated before or during machining. Ozler et al stated in their research on Heating of the material makes high hardness of the material become soft, resulting in improved machinability, high production rate and Low power consumption from all these advantages hot machining is extremely used full to machine hard to cut materials like ceramics. Thandra et al. (2010) conducted experiments in both conventional and hot machining and they observed that hot machining was effective in bringing down the cutting forces, surface roughness and flank wear by about $34 \%$.

\section{Problem Identification:}

The identification of turning problem for OHNS Steel rods which cannot be tackled using Conventional technique because of following problems occurs in turning process.

- High surface roughness.

- Difficult to achieve Close tolerance

- Machining distortion.

- Poor Chip Breaking.

- Need more cutting pressure for machining and Need of High Hardness Cutting tool.

\section{Experimental Details}

The OHNS steel of $32 \mathrm{~mm}$ diameter as work piece used in these experiments. The chemical compositions of OHNS steel is shown in Table1.

\begin{tabular}{|l|l|l|l|l|}
\hline $\mathrm{C} \%$ & $\mathrm{Mn} \%$ & $\mathrm{Si} \%$ & $\mathrm{~S} \%$ & $\mathrm{P} \%$ \\
\hline 0.919 & 1.343 & 0.281 & 0.140 & 0.064 \\
\hline $\mathrm{V} \%$ & $\mathrm{Al} \%$ & $\mathrm{C} \%$ & $\mathrm{Tin} \%$ & $\mathrm{~W} \%$ \\
\hline 0.002 & 0.020 & 0.060 & 0.007 & 0.375 \\
\hline $\mathrm{Cr} \%$ & $\mathrm{Ni} \%$ & $\mathrm{Mo} \%$ & $\mathrm{Ti} \%$ & $\mathrm{~B} \%$ \\
\hline 0.570 & 0.127 & 0.059 & 0.004 & 0.00242 \\
\hline $\mathrm{Co} \%$ & $\mathrm{Nb} \%$ & $\mathrm{~Pb} \%$ & & \\
\cline { 1 - 2 } & & & & \\
\cline { 1 - 2 } & 0.021 & 0.001 & &
\end{tabular}


Table: 1 Chemical Composition of OHNS steel TiAlN Coated Carbide insert is specified as cutting tool as shown in Fig:1. It is prepared with the thickness ranges between 2 to 4 microns and the Oxidation temperatures between $1652^{\circ} \mathrm{F} / 900^{\circ} \mathrm{F}$. The hardness is typically Hv2800. Properties of TiAlN coated carbide inserts are Coating thickness: $0.0025 \mathrm{~mm}-0.005 \mathrm{~mm}$

Hardness: 4000 - $4200 \mathrm{HV}$

Deposition Temp: $700-800^{\circ} \mathrm{F}$

This Coating is known as the "Black" titanium coating

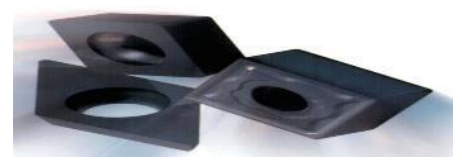

Fig:1 Ti AlN Carbide Insert

The process parameter ranges were decided on the basis of machine capability and pilot experiments. In this paper L18 orthogonal array is employed to analyze experimental results of machining obtained from 18 experiments for hot machining individually varying three parameters speed, feed rate, Depth of cut. For conducting experiments, an oxy acetylene heating setup was used to heat the work piece material. Oxy acetylene heating is one of the best choices for hot machining it requires low cost equipment the heat transfer to the work piece is very low, although the gross heat available and the energy transfer density will be low and metallurgical damage of the work piece is low. The flame was generated through the nozzle of torch. A special attachment was used to move the torch mounted on carriage to provide a flexible movement of heat source while machining. During all the experiments, the distance between the torch and work piece is $25 \mathrm{~mm}$. Flow rates for acetylene and oxygen were adjusted by pressure regulator and kept constant to get a neutral flame, which was used throughout the machining.

The machine Set up is shown in Fig: 2

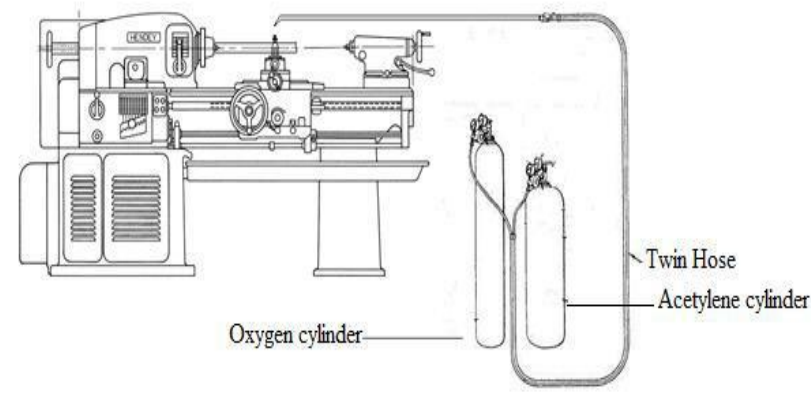

Fig: 2 Machine Setup

The work piece is maintained to a temperature between $385^{\circ} \mathrm{C}-410^{\circ} \mathrm{C}$ with the help of neutral flame heating with Oxyacetylene gas.

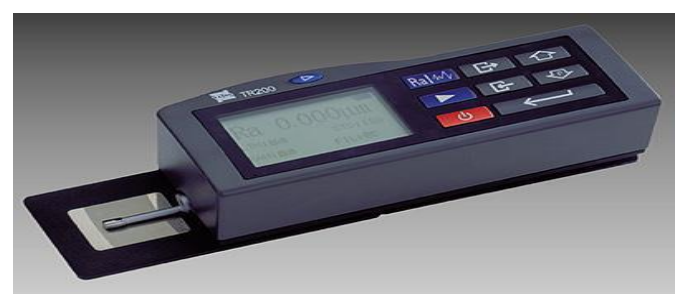

Fig: 3 Surface roughness tester TR 200

In this project, surface roughness tester is used to find the surface roughness of the work piece. After machining the work piece is place on a flat table and probe of the roughness tester is placed on the work piece and play button is pressed, the value of the roughness of the area is shown on the LED screen and value is noted. Similarly the roughness is measured for five different areas on the work piece. The average of the five values gives the roughness of the work piece. The various input parameters are speed, feed and depth of cut. The various output parameters measured are material removal rate, surface roughness. 


\subsection{Design of Experiments:}

Taguchi method is a powerful tool for the design of high quality systems. It provides a simple, efficient and systematic approach to optimize design for performance, quality and cost. To study effect of process parameters like Speed, feed and depth of cut on two important Performance characteristics surface roughness, MRR. Based on the degree of freedom of process parameters, L18 orthogonal array is selected.

Accordingly, 18 experiments were carried out to study the effect of machining process parameters on performance characteristics.

\begin{tabular}{|c|c|c|c|}
\hline Factor & Type & Levels & Values \\
\hline \multirow{3}{*}{ Speed } & \multirow{3}{*}{ Fixed } & \multirow{3}{*}{3} & 0.293 \\
\hline & & & 0.418 \\
\hline & & & 0.523 \\
\hline \multirow{3}{*}{ Feed } & \multirow{3}{*}{ Fixed } & \multirow{3}{*}{3} & 0.05 \\
\hline & & & 0.10 \\
\hline & & & 0.16 \\
\hline \multirow{3}{*}{ Doc } & \multirow{3}{*}{ Fixed } & \multirow{3}{*}{3} & 0.5 \\
\hline & & & 1.0 \\
\hline & & & 1.5 \\
\hline
\end{tabular}

Table 1: Machining Parameters

\section{Results And Discussions}

After the completion of all the 18 experiments, the following results were obtained by machining of OHNS steel. The S/N ratio, Regression Equation and the ANOVA values for DOE approach were calculated by putting the values of MRR and Surface Roughness in Minitab software. S/N value should be

Maximum to get optimum response. Table 2 shows the experimental results and Fig 4 shows main effect Plot for $\mathrm{S} / \mathrm{N}$ ratios with Nominal is best method.

\begin{tabular}{|c|c|c|c|c|c|c|c|}
\hline $\begin{array}{c}\text { SI } \\
\text { NO }\end{array}$ & SPEED & FEED & DOC & $\begin{array}{c}\text { MRR-DM } \\
\text { gm/min }\end{array}$ & $\begin{array}{c}\text { MRR-HM } \\
\text { gm/min }\end{array}$ & $\begin{array}{c}\text { SR }(\mathrm{Ra}) \\
\text { DM }(\mu)\end{array}$ & $\begin{array}{c}\text { SR }(\mathrm{Ra}) \\
\mathrm{HM}(\mu)\end{array}$ \\
\hline 1 & 0.293 & 0.05 & 0.5 & 3.5 & 5.35 & 4.107 & 1.498 \\
\hline 2 & 0.293 & 0.1 & 1.0 & 13.6 & 16.27 & 3.307 & 0.898 \\
\hline 3 & 0.293 & 0.16 & 1.5 & 29.2 & 34.04 & 3.7 & 1.4 \\
\hline 4 & 0.418 & 0.05 & 0.5 & 5.31 & 8.55 & 2.143 & 0.874 \\
\hline 5 & 0.418 & 0.1 & 1.0 & 19.4 & 22.3 & 2.765 & 1.057 \\
\hline 6 & 0.418 & 0.16 & 1.5 & 31.2 & 35.6 & 3.265 & 0.957 \\
\hline 7 & 0.523 & 0.05 & 1.0 & 11.58 & 13.95 & 3.23 & 1.289 \\
\hline 8 & 0.523 & 0.1 & 1.5 & 22.75 & 24.89 & 2.82 & 1.263 \\
\hline 9 & 0.523 & 0.16 & 0.5 & 17.4 & 20.8 & 2.32 & 0.78 \\
\hline 10 & 0.293 & 0.05 & 1.5 & 10.63 & 13.98 & 1.602 & 0.97 \\
\hline 11 & 0.293 & 0.1 & 0.5 & 5.71 & 9.88 & 4.307 & 1.698 \\
\hline 12 & 0.293 & 0.16 & 1.0 & 21.94 & 23.47 & 3.57 & 1.12 \\
\hline 13 & 0.418 & 0.05 & 1.0 & 9.8 & 12.5 & 3.565 & 0.957 \\
\hline 14 & 0.418 & 0.1 & 1.5 & 25.8 & 28.4 & 3.82 & 1.26 \\
\hline 15 & 0.418 & 0.16 & 0.5 & 18.48 & 23.15 & 3.47 & 1.202 \\
\hline 16 & 0.523 & 0.05 & 1.5 & 17.37 & 19.54 & 2.827 & 1.212 \\
\hline 17 & 0.523 & 0.1 & 0.5 & 11.03 & 16.46 & 2.3 & 0.89 \\
\hline
\end{tabular}

Table 2: Experimental Results of Hot Machining 


\section{ANALYSIS OF MRR:}

\begin{tabular}{|c|c|l|l|c|c|}
\hline Source & DF & Adj SS & Adj MS & $\begin{array}{c}\text { F- } \\
\text { Value }\end{array}$ & $\begin{array}{c}\text { P- } \\
\text { Value }\end{array}$ \\
\hline Speed & 2 & 80.83 & 40.416 & 8.24 & 0.007 \\
\hline Feed & 2 & 785.02 & 392.51 & 80.03 & 0.000 \\
\hline Doc & 2 & 435.54 & 217.768 & 44.40 & 0.000 \\
\hline Error & 11 & 53.95 & 4.905 & & \\
\hline Total & 17 & 1355.34 & \multicolumn{3}{|c}{} \\
\cline { 1 - 4 } & & & &
\end{tabular}

Table 3: ANOVA for $\mathrm{S} / \mathrm{N}$ ratio of MRR

The purpose of ANOVA analysis is to find the effect of design parameters on quality characteristics. The results of ANOVA which was done to determine the significant level of variable on the Ra obtained during the hot turning of OHNS steel is given in Table 3 .

The Regression analysis is done with the input factors towards the performance parameters and the Regression Equation for Material removal Rate is given below

\section{Regression Equation:}

MRR $\mathrm{HM}=20.160 \quad-2.995$ Speed_0.293

+ 1.590 Speed_0.418+1.405 Speed_0.523-

7.848 Feed_0.05-0.460 Feed_0.10

+ 8.308 Feed_0.16-6.128 Doc_0.5

+0.213 Doc_1.0+5.915 Doc_1.5

Response Table for Signal to Noise Ratios for MRR HM (Nominal is the Best)

\begin{tabular}{|c|c|c|c|}
\hline Level & Speed & Feed & Doc \\
\hline 1 & 16.18 & 14.85 & 12.29 \\
\hline 2 & 17.51 & 17.49 & 20.14 \\
\hline 3 & 19.27 & 20.62 & 20.53 \\
\hline Delta & 3.09 & 5.77 & 8.24 \\
\hline Rank & 3 & 2 & 1 \\
\hline
\end{tabular}

Table 4: Ranking of Parameters for MRR From the above table it is observed that Doc is the dominating factor followed by feed and spindle speed of Turning operation of OHNS steel.

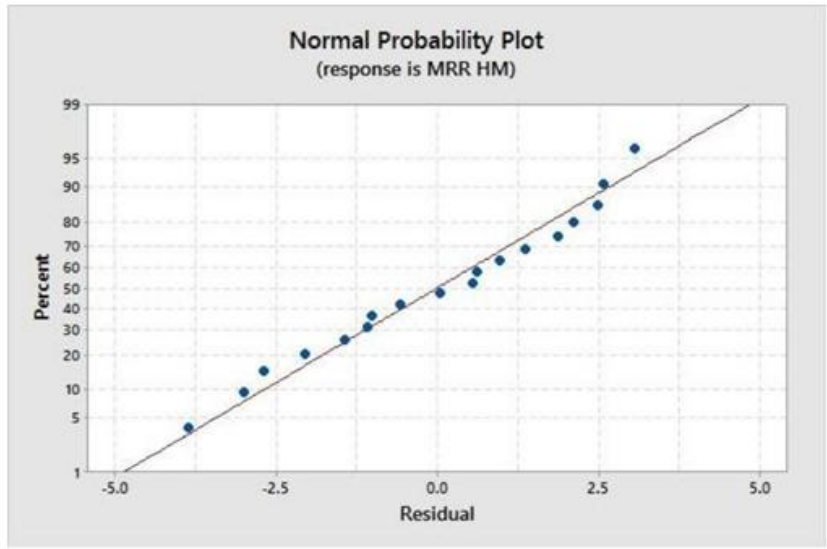




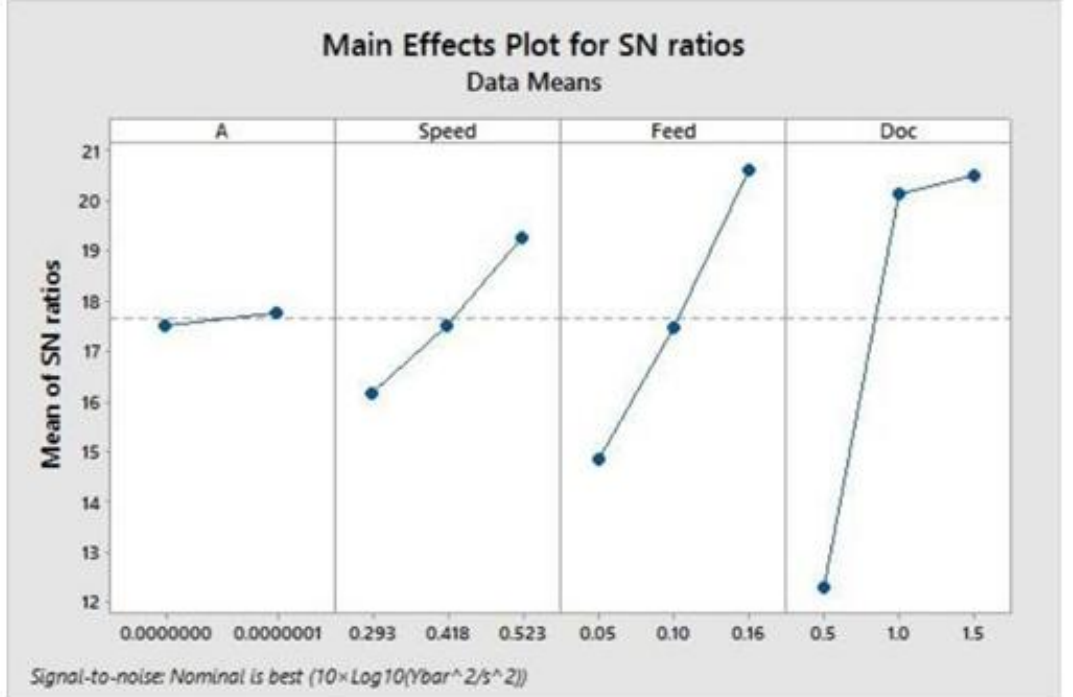

Fig 4: Main effect plot of S/N ratios of MRR

From the above graphs it is observed that the MRR is having an increasing trend with the increase in DOC and Feed. MRR increases with increase in cutting speed. The most important reason for increase in MRR is found to be DOC having highest significance $96.02 \%$ contribution.

\section{ANALYSIS OF SURFACE ROUGHNESS}

Analysis of surface roughness (Ra) is given Below.

\section{Analysis of Variance:}

\begin{tabular}{|l|l|l|l|l|c|}
\hline Source & DF & Adj SS & Adj MS & $\begin{array}{l}\text { F- } \\
\text { Value }\end{array}$ & $\begin{array}{c}\text { P- } \\
\text { Value }\end{array}$ \\
\hline Speed & 2 & 0.14738 & 0.073689 & 1.01 & 0.397 \\
\hline Feed & 2 & 0.01486 & 0.007429 & 0.10 & 0.904 \\
\hline Doc & 2 & 0.02799 & 0.013993 & 0.19 & 0.829 \\
\cline { 1 - 3 } Error & 11 & 0.80475 & 0.073159 & & \\
\cline { 1 - 3 } Total & 17 & 0.99497 & \multicolumn{3}{|l}{} \\
\cline { 1 - 3 } & & & & &
\end{tabular}

Table 5: ANOVA for S/N ratio of Surface Roughness

\section{Regression Equation:}

SR HM $=1.1397+0.1243$ Speed_0.293-

0.0886 Speed_0.418- 0.0357 Speed_0.523-

0.0064 Feed_0.05+ 0.0379 Feed_0.10-

0.0316 Feed_0.16+0.0173 Doc_0.5-

0.0546 Doc_1 $1.0+0.0373$ Doc_1.5 
Response Table for Signal to Noise Ratios Nominal is best

\begin{tabular}{|l|l|l|l|}
\hline Level & Speed & Feed & Doc \\
\hline 1 & 4.235 & 4.729 & 3.798 \\
\hline 2 & 3.119 & 3.739 & 3.421 \\
\hline 3 & 4.630 & 3.515 & 4.763 \\
\hline Delta & 1.511 & 1.214 & 1.342 \\
\hline Rank & 1 & 3 & 2 \\
\hline
\end{tabular}

Table 6: Ranking of Parameters for Surface Roughness

From the above table it is observed that Spindle speed is a dominating parameter of surface roughness of turning process. However OHNS Steel plate having good machinability characteristic and Produce reasonable surface finish. During turning process all parameters are interact and dependantable in turning operation. It was noted that with increase in temperature and depth of cut up to level 2 better surface finish was obtained and with low feed and high speed, better surface finish was obtained.
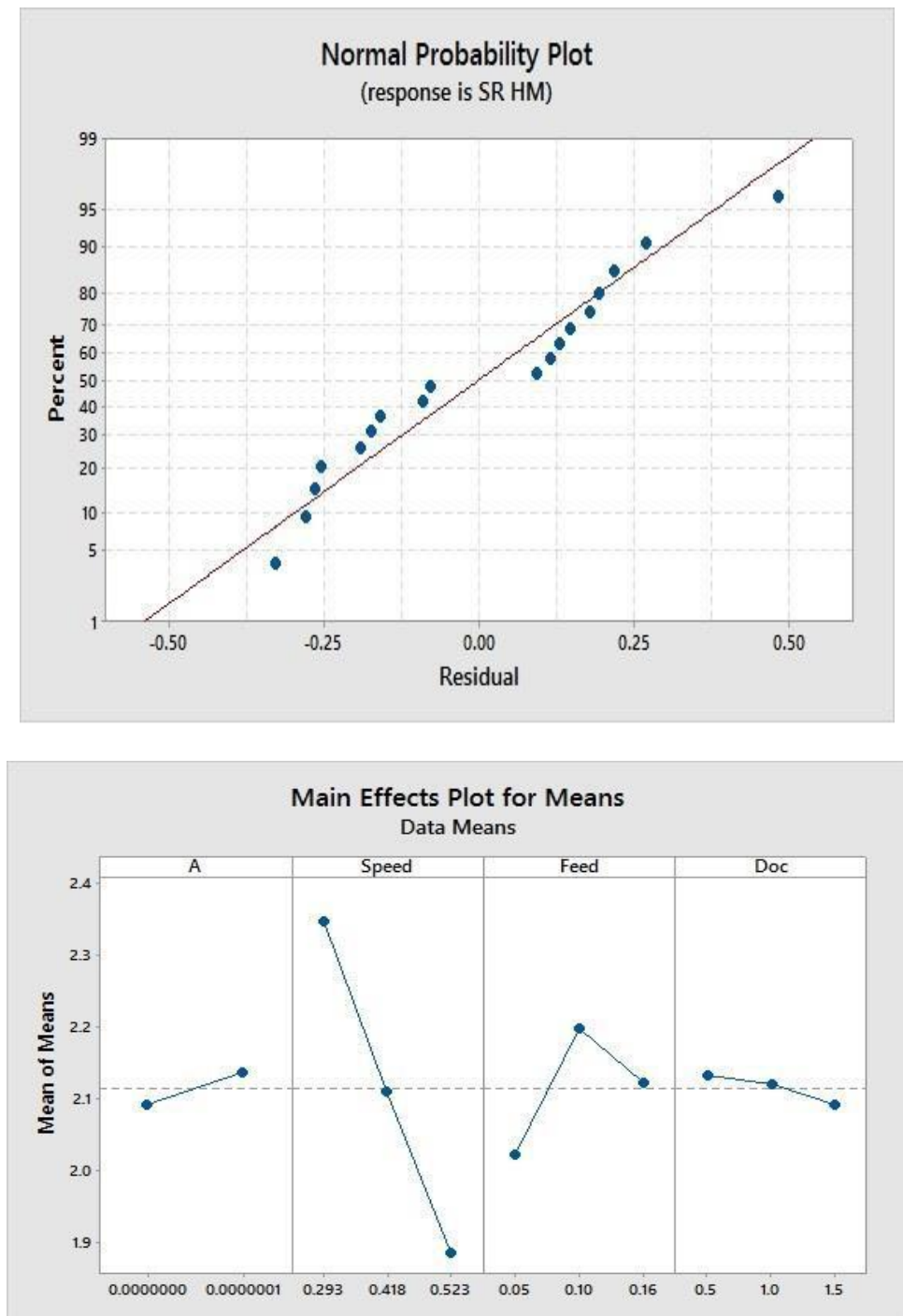

Fig 5: Main effect plot of S/N ratios of Surface Roughness

The Fig 5 indicates that as the cutting speed Increases, the surface roughness decreases. Similarly results of Surface Roughness for depth of cut $1.5 \mathrm{~mm}$ are calculated. 


\section{Conclusions}

In this study the statistical method of signal-to-noise ratio (S/N) and (ANOVA) were applied to evaluate the effect of processes parameters on surface roughness and metal removal rate and to find the optimal processes parameters to minimize the surface roughness and to maximize the metal removal rate during hot machining of OHNS steel. The results obtained from this study are given below:

- The smallest Surface Roughness(Ra) values occurred during hot machining of OHNS steel are obtained as $0.78 \mu \mathrm{m}$ from the experiments performed at $250 \mathrm{rpm}$ cutting speed, $0.16 \mathrm{~mm} / \mathrm{rev}$ feed rate, 0.5 depth of cut.

- The highest MRR values occurred during hot machining of OHNS stainless steel are obtained at $200 \mathrm{rpm}$, $0.16 \mathrm{~mm} / \mathrm{rev}$ feed rate, $1.5 \mathrm{~mm}$ depth of cut.

- The effects of the variables on surface roughness and metal removal rate were determined by ANOVA. Cutting speed and depth of cut are the significant parameters.

\section{References}

[1]. S. Ranganathan and T. Senthivelan (2010), "Optimizing the process parameters on tool wear of WC inert when hot turning of AISI 316 Stainless steel, “Asian Research Publishing Network (ARPN), Vol. 5, No.7, pp. 24-35.

[2]. M. Davami and M. Zadshakoyan (2008), "Investigation of Tool Temperature and Surface Quality in Hot machining of Hard-to-Cut materials," World Academy of Science, Engineering and Technology, 46

[3]. T.Kitagawa and K.Maekawa (1990), Plasma Hot Machining for new Engineering materials. Wear, Vol.139, pp.251-26.

[4]. Pal D. K., Basu S. K. (1971), Hot machining of austenitic manganese steel by shaping, International Journal of Machine Tool Design Research, Vol. 11, pp. 45-61.

[5]. L. Ozler and A. Inan (2001), "Theoretical and Experimental determination of tool life in Hot machining of Austenitic manganese steel," International Journal of Machine Tools \& Manufacturer, 41, pp.163-172

[6]. K.P. Maity and P.K. Swain (2008), "An experimental investigation of Hot-machining to predict tool life," Journal of Material Processing Technology, 198, 344-349

[7]. N. Satheesh Kumar, Ajay Shetty, Ashay Shettyb, Ananth K, Harsha Shetty, (2012),'Effect of spindle speed and feed rate on surface roughness of Carbon Steels in CNC turning", International Conference on Modeling, Optimization and Computing (ICMOC 2012), Procedia Engineering, Elsevier.

[8]. Lei,Y.C. Shin, F.P. Incropera (2001), "Experimental investigation of thermo-mechanical characteristics in laser assisted machining of silicon nitride ceramics", Journal of Manufacturing Science \& Engineering, Vol. 123, pp.639-646.

[9]. ThandraS.K.andChoudhury S.K.(2010), "Effect of cutting parameters on cutting force, surface finish and tool wear in hot machining”, International Journal of Machining and Machinability of Materials, Vol. 7, pp.260 - 273 